\title{
THE FEATURES OF PROCEDURAL AND NON-PROCEDURAL FORMS OF THE COUNSEL'S ACTIVITY AND THEIR DIFFERENTIATION
}

\author{
Viktor V. Zaborovsky \\ Uzhgorod National University, Uzhgorod, Ukraine
}

\begin{abstract}
Introduction: the proper disclosure of the legal status of the counsel is impossible without investigating the legal nature of the procedural and non-procedural forms of his activities, in particular, in the context of their differentiation. This distinction allows not only finding out the specifics of the legal status of the counsel when providing legal assistance in a particular type of procedural proceedings, but also separating the status of the counsel from the status of other persons who are entitled to provide legal services. The purpose of the paper is to reveal the essence of the procedural and non-procedural forms of the counsel's activity in the aspect of his providing legal assistance. The main author's tasks are: to reveal the essence of the classification of the legal status of an individual by nature (content) in the context of its impact on the status of the counsel; to analyze the legal nature of the procedural and non-procedural forms of the counsel's activity; to establish the practical value in differentiating such forms of the lawyer's activity and to find out the relationship between them. Methods: the methodological framework for the research is a set of methods of scientific knowledge, among which the main ones are the dialectical method, the method of system analysis and synthesis. Results: the paper indicates the existence of a general (constitutional), professional and individual legal status of the counsel, which is characterized by the possibility of distinguishing the procedural and non-procedural forms of the counsel's activity. Conclusions: the author argues for the position that the individual status of the counsel is characterized by the possibility of distinguishing the procedural and non-procedural forms of the counsel's activity when providing legal assistance by him. At the same time, regardless of whether the counsel implements the procedural or non-procedural form of his activity, he retains the professional status of the counsel, and such a person should be properly referred to as the defense counsel, representative counsel, or the term "counsel", for example, when providing legal assistance to a witness.
\end{abstract}

Key words: counsel, legal status of the counsel, individual (professional) status of the counsel, forms of legal activity, procedural form of the counsel's activity, non-procedural form of the counsel's activity.

Citation. Zaborovsky V.V. The Features of Procedural and Non-Procedural Forms of the Counsel's Activity and Their Differentiation. Legal Concept, 2020, vol. 19, no. 3, pp. 108-116. (in Russian). DOI: https://doi.org/ 10.15688/lc.jvolsu.2020.3.15

\section{ОСОБЕННОСТИ ПРОЦЕССУАЛЬНОЙ И НЕПРОЦЕССУАЛЬНОЙ ФОРМ ДЕЯТЕЛЬНОСТИ АДВОКАТА И ИХ РАЗГРАНИЧЕНИЕ}

\author{
Виктор Викторович Заборовский \\ Ужгородский национальный университет, г. Ужгород, Украина
}


Введение: надлежащее раскрытие правового статуса адвокат невозможно без исследования правовой природы процессуальной и непроцессуальной форм его деятельности, в частности, в контексте их разграничения. Последнее позволяет не только выяснить особенности правового положения адвоката при оказании правовой помощи в том или ином виде процессуального судопроизводства, но и отделить статус адвоката от статуса других лиц, которые наделяются правом предоставлять правовые услуги. Целью данной статьи является раскрытие сущности процессуальной и непроцессуальной формы деятельности адвоката в аспекте предоставления им правовой помощи. Автор ставит перед собой такие задачи, как: раскрыть сущность классификации правового статуса личности по характеру (содержанию) в контексте ее влияния на статус адвоката; проанализировать правовую природу процессуальной и непроцессуальной форм деятельности адвоката; установить практическую ценность в разграничении таких форм деятельности адвоката и выяснить взаимосвязь между ними. Методы: методологическую основу данного исследования составляет совокупность методов научного познания, среди которых основное место занимают диалектический метод, метод системного анализа и синтеза. Результаты: в статье указывается на существование общего (конституционного), профессионального и индивидуального правового статуса адвоката, который характеризуется возможностью выделения процессуальной и непроцессуальной формы деятельности адвоката. Выводы: аргументируется позиция, согласно которой индивидуальный статус адвоката характеризуется возможностью выделения процессуальной и непроцессуальной формы деятельности адвоката при предоставлении им правовой помощи. При этом, независимо от того, реализует адвокат процессуальную или непроцессуальную форму своей деятельности, за ним сохраняется профессиональный статус адвоката, и такое лицо должно собственно именоваться адвокат-защитник, адвокат-представитель или же термином «адвокат», например, при предоставлении правовой помощи свидетелю.

Ключевые слова: адвокат, правовой статус адвоката, индивидуальный (профессиональный) статус адвоката, формы адвокатской деятельности, процессуальная форма деятельности адвоката, непроцессуальная форма деятельности адвоката.

Цитирование. Заборовский В. В. Особенности процессуальной и непроцессуальной форм деятельности адвоката и их разграничение // Legal Concept = Правовая парадигма. $-2020 .-$ T. 19, № 3. - C. 108-116. DOI: https://doi.org/10.15688/lc.jvolsu.2020.3.15

\section{Введение}

Важную роль в механизме защиты прав и свобод человека и гражданина играет профессиональная деятельность адвоката, на которого возлагается конституционная обязанность по предоставлению правовой помощи каждому человеку. Такой конституционный долг реализуется в процессе осуществления им определенной разновидности адвокатской деятельности, которая происходит в пределах процессуальной и непроцессуальной ее форм. Актуальность данной темы научного исследования проявляется в том, что разделение процессуальной и непроцессуальной формы деятельности адвоката дает возможность, с одной стороны, более детально проанализировать статус адвоката во время предоставления им правовой помощи своему клиенту в том или ином виде процессуального судопроизводства, а с другой - разграничить правовой статус адвоката от статуса других лиц, которые наделяются правом предоставлять правовые услуги.

\section{Изложение основного материала}

Исследуя вопрос о сущности правового статуса личности в аспекте его влияния на статус адвоката, необходимо обратить внимание на то, что в юридической литературе имеются различные критерии классификации правового статуса личности и в частности адвоката. Однако общепризнанным является критерий классификации правового статуса личности по характеру (содержанию). По такому критерию различают: общий (конституционный) статус; специальный (родовой) и индивидуальный статус [19, с. 290; 23, с. 44].

Раскрывая сущность такой классификации правового статуса лица, нужно учесть утверждение Н.И. Матузова, который указывает на то, что эти «три вида статуса соотносятся между собой как общее, особенное и единичное. Они тесно взаимосвязаны и взаимозависимы, наслаиваются друг на друга, на практике неразделимы. Каждый индивид выступает одновременно во всех указанных качествах» [21, с. 268]. Учитывая специфику правового статуса адвоката, в разрезе дан- 
ной классификации, можно прийти к выводу, что общий (конституционный) статус лица, являющегося адвокатом, соответствует правовому статусу физического лица (поскольку в соответствии с законодательством адвокатами могут быть только физические лица); специальный (родовой) статус такого лица составляет совокупность профессиональных прав, обязанностей и других элементов статуса (предусмотрены, в частности, в Украине - Законом Украины «Об адвокатуре и адвокатской деятельности» и Правилами адвокатской этики, в России - Федеральным законом «Об адвокатской деятельности и адвокатуре в Российской Федерации» и Кодексом профессиональной этики адвоката); индивидуальный правовой статус адвоката представляет собой его правовое положение во время предоставления им конкретных видов правовой помощи (защиты, представительства и предоставления других видов правовой помощи).

В аспекте нашего исследования, учитывая то, что основным назначением адвоката является оказание правовой помощи на профессиональной основе, специальный (родовой) статус такого лица, по нашему мнению, может получить название профессионального. Фактически с таких позиций исходит и В.Г. Андрусев, указывающий на «наличие у адвоката специального (особого) правового статуса, который обусловлен его профессией» [2, c. 196].

Выяснив критерии классификации видов правового статуса личности и придя к выводу, что специальный (родовой) статус адвоката может получить название профессионального, нужно учесть и то, что в юридической литературе имеются и точки зрения ученых, по которым такой вид статуса имеет и свою внутреннюю классификацию. В данном случае заслуживает внимания позиция Е.Г. Мартынчик, который новизну и нетрадиционность исследования статуса адвоката прежде всего видит в его дифференцированной трактовке, что проявляется в существовании самостоятельных статусов: организационно-правового и процессуально-правового статуса адвоката. Первый статус, который он считает приоритетным, по его определению, является единым для всех адвокатов в качестве членов адвокатской корпорации и закреплен в Законе об адвокатской деятельности и адвокатуре, тогда как процессуально-правовой статус он рассматривает в качестве производного от организационного, что представляет собой совокупность процессуальных правоотношений на уровне «государство - адвокат», которые урегулированы законодательством о различных видах судопроизводства, что накладывает свой отпечаток на процессуально-правовой статус адвоката, определяет его особенности, структуру, содержание [13, с. 57-58].

Подобной точки зрения придерживается и А.М. Бирюкова, которая отмечает, что деятельность адвоката в уголовном процессе нужно рассматривать под углом разграничения статуса адвоката-защитника на общеправовой и уголовно-процессуальный, поскольку правовая помощь адвоката в уголовном процессе не ограничивается его процессуальным статусом защитника в деле, учитывая возможность предоставления предварительной правовой помощи лицам до вступления в дело в качестве защитника $[4$, с. 11]. Почти из таких же позиций исходит и О.Д. Гоматина, которая отмечает, что законодательством об адвокатуре предоставляется общий статус адвоката, тогда как процессуальный зависит от процессуального положения доверителя [6, с. 67].

Для исследования внутренней классификации профессионального статуса адвоката, по нашему мнению, прежде всего необходимо провести анализ природы процессуальной и непроцессуальной (внепроцессуальной) деятельности адвоката. Мы разделяем позицию Е.А. Леонтьевой [12, с. 14], которая в зависимости от норм, регулирующих предоставление адвокатом юридической помощи, различает процессуальную и непроцессуальную формы ее предоставления. Она указывает на то, что первая форма опирается на нормы процессуальных кодексов и тем самым всегда облекается в процессуальную форму, а вторая - на нормы и предписания других законов и нормативных актов, принципы и нормы адвокатской этики. По нашему мнению, независимо от того, реализует адвокат процессуальную или непроцессуальную форму своей деятельности, за ним сохраняется профессиональный статус адвоката, и такое лицо должно именоваться адвокат-защитник, адвокат- 
представитель или же термином «адвокат», например, при предоставлении правовой помощи свидетелю.

Следует обратить внимание на то, что в юридической литературе некоторые ученые для разграничения процессуальной и непроцессуальной деятельности адвоката используют термин «виды», а не «формы». В частности, А.А. Венедиктов и Ю.Е. Венедиктова четко разграничивают два вида представительской деятельности адвоката - процессуальную (такая, что осуществляется в рамках административного, хозяйственного, уголовного и гражданского процесса) и внепроцессуальную (не связанная с досудебным следствием и рассмотрением дел в суде) [5, с. 146]. Мы не разделяем такой точки зрения, а придерживаемся позиции Э.Е. Колоколовой, которая исходит из того, что «если формы адвокатской юридической помощи отвечают на вопрос о том, как действовать представителю в гражданском судопроизводстве, чтобы профессионально выполнить поручение, то виды юридической помощи дают представление о том, что уполномочен делать адвокат-представитель по гражданским делам в рамках названных форм» [11, с. 32]. Подобной точки зрения придерживается В. Заботин, отмечая, что под формой оказания помощи в судопроизводстве нужно понимать закрепление в нормах процессуального законодательства способа организации и осуществления правовой помощи, а различные виды правовой помощи могут предоставляться в рамках одной из его форм, поскольку виды входят в содержание правовой помощи, а формы ее предоставления являются способами не только организации, но и осуществления на практике содержания такой помощи [8, с. 67].

Фактически с таких позиций исходит и украинский законодатель, который в ст. 19 Закона Украины «Об адвокатуре и адвокатской деятельности» [17] раскрывает виды адвокатской деятельности, что, по нашему мнению, лишь указывает на ориентировочные направления деятельности адвоката для выполнения возложенной на него обязанности по предоставлению правовой помощи. Аналогичной позиции придерживается и российский законодатель (ч. 2 и 3 Федерального закона «Об адвокатской деятельности и адвокатуре в
Российской Федерации» [14]). В свою очередь, анализ п. 6 ч. 1 ст. 1 Закона Украины, в котором раскрывается дефиниция понятия «другие виды правовой помощи», дает нам возможность прийти к выводу, что украинский законодатель определенным образом осуществляет и разграничение процессуальной и непроцессуальной деятельности адвоката, поскольку одной из разновидностей указанных других видов правовой помощи он рассматривает составления процессуальных и других документов правового характера, направленных на обеспечение реализации прав, свобод и законных интересов клиента.

Для полноты проведенного нами исследования, необходимо различать и понятие «организационные формы адвокатской деятельности», согласно которому адвокат может осуществлять адвокатскую деятельность индивидуально или в организационно-правовых формах адвокатского бюро или адвокатского объединения (ч. 3 ст. 4 Закона Украины). В свою очередь, законодательство Российской Федерации предусматривает, что формами адвокатских образований являются: адвокатский кабинет, коллегия адвокатов, адвокатское бюро и юридическая консультация (ч. 1 ст. 20 Федерального закона). Мы придерживаемся позиции, согласно которой указанное понятие отражает не процессуальную или непроцессуальную форму деятельности адвоката, а воспроизводит, как отмечает Е.С. Сивкова [20], правовую модель для реализации функций адвокатуры, защиты прав адвокатских объединений и адвокатов, самостоятельно избирается адвокатом. Указанное дает нам возможность прийти к выводу о целесообразности использования правовой конструкции о процессуальной и непроцессуальной формах, а не видах деятельности адвоката о предоставлении правовой помощи.

Процессуальная форма предоставления адвокатом правовой помощи охватывает всю совокупность процессуальных действий, которые разрешены соответствующим процессуальным законодательством. Например, адвокат-представитель в гражданском производстве в соответствии с ч. 1 ст. 44 ГПК Украины может совершать от имени лица, которое он представляет, все процессуальные действия, которые имеет право совершать это 
лицо (почти аналогичные положения воспроизведены и в ч. 1 ст. 54 ГПК РФ). Такой нормой устанавливается общее правило участия адвоката в гражданском производстве от имени лица, которое он представляет. При этом реализация любого права человека, интересы которого представляет адвокат, и на любых стадиях гражданского судопроизводства должна происходить в точном соответствии с требованиями такого судопроизводства.

Что касается непроцессуальной формы деятельности адвоката, то мы придерживаемся точки зрения, согласно которой она, по сравнению с процессуальной формой предоставления адвокатом правовой помощи, носит вспомогательный характер, может предшествовать или сопровождать процессуальную форму [22, c. 20]. Несомненно, что по значению и объему центральное место занимает процессуальная форма деятельности адвоката, но ни в коем случае не следует преуменьшать и роль непроцессуальной формы деятельности. В связи с этим заслуживает внимания позиция ученых, которые указывают на то, что значительный объем среди видов адвокатской деятельности занимает предоставление консультаций и разъяснений по юридическим вопросам, составление заявлений, жалоб и других документов правового характера, в том числе и при непосредственном обращении клиента к адвокату $[15$, с. 47]. Кроме того, как отмечает С.В. Кирюшина, адвокат начинает работу по гражданскому делу задолго до возникновения гражданского процесса и часто до оформления представительских полномочий. Исследователь обращает внимание на то, что умаление значения данного этапа с точки зрения бездействия адвоката как представителя стороны в гражданском процессе является недальновидным и неоправданным, поскольку от правильного предоставления адвокатом юридической помощи на досудебной стадии зависит эффективность и в конечном итоге результат участия адвоката в судебном разбирательстве [9, с. 20].

Мы разделяем указанную позицию ученых, поскольку:

1. На практике достаточно распространены случаи, когда непроцессуальная форма деятельности адвоката является более содержательной и объемной по сравнению с процессуальной.
2. От того, насколько компетентно и правильно будет составлено обращение и самое главное - убедительно обоснована правовая позиция, во многом зависит исход дела [7, c. 1632].

Вообще, по нашему мнению, определить эффективность деятельности адвоката по оказанию правовой помощи можно только на основании анализа как процессуальной, так и непроцессуальной формы его деятельности.

Исследуя природу непроцессуальной формы деятельности адвоката, нужно обратить внимание на то, что она, несмотря на свое название, не характеризуется отсутствием правового регулирования по ее осуществлению, то есть не означает возможности адвоката осуществлять такую деятельность по своему усмотрению. Нужно не забывать, что такая форма деятельности адвоката регулируется, в частности, законодательством об адвокатуре, основные источники которого - соответствующий профильный закон и Правила адвокатской этики (Кодекс профессиональной этики адвоката). Так, этими актами предусмотрено, что одним из основных принципов осуществления адвокатской деятельности является принцип законности. Последний детализируется в ст. 7 Правил адвокатской этики [16] (соблюдение законности), в которой предусмотрено, что в своей профессиональной деятельности адвокат обязан в том числе соблюдать действующее законодательство Украины, способствовать утверждению и практической реализации принципов верховенства права и законности. Заслуживает внимания и положение ч. 1 ст. 10 Кодекса профессиональной этики адвоката [10], согласно которому закон и нравственность в профессии адвоката выше воли доверителя, и никакие пожелания, просьбы или требования доверителя, направленные к несоблюдению закона или нарушению правил, предусмотренных настоящим Кодексом, не могут быть исполнены адвокатом. То есть непроцессуальная форма деятельности адвоката по своему содержанию тоже является правовой, поскольку урегулирована нормами, в частности, законодательства об адвокатуре, и осуществляется в интересах клиента с помощью средств, не запрещенных законом.

Практическая ценность в разграничении процессуальной и непроцессуальной форм де- 
В.В. Заборовский. Особенности процессуальной и непроцессуальной форм деятельности адвоката

ятельности адвоката заключается в том, что оно дает нам возможность более детально проанализировать статус адвоката во время предоставления им правовой помощи своему клиенту в том или ином виде процессуального судопроизводства. Фактически на основании разграничения таких форм его деятельности ряд ученых выделяет как специальные и отраслевые права, так и соответственно специальный и отраслевой статус адвоката.

В данном случае заслуживает внимания позиция А.В. Рагулина, который указывает на разницу в правовом статусе адвоката и адвоката-защитника. В частности, ученый выделяет «два уровня профессиональных прав адвоката-защитника: первый уровень - специальный, который установлен Ф3 «Об адвокатской деятельности...», второй уровень - отраслевой, установленный положениями Криминально-процессуального законодательства и процессуальными нормами законодательства об административных правонарушениях» [18, с. 52]. При этом А.В. Рагулин отмечает, что полномочия адвоката-защитника более широкие, так как он в дополнение к полномочиям, которые предусмотрены законодательством об адвокатуре, приобретает и права, предусмотренные процессуальным законодательством.

Исследование природы процессуальной и непроцессуальной форм деятельности адвоката также дает нам возможность отграничить правовой статус адвоката от статуса других лиц, которые наделяются правом предоставлять правовые услуги. Например, в украинском гражданском судопроизводстве представителем (по малозначительным делам) может быть адвокат или иное лицо, достигшее восемнадцати лет, которое имеет гражданскую процессуальную дееспособность. При этом, в отличие от таких лиц, адвокат вправе выполнять свои ролевые функции по оказанию юридической помощи как в процессуальной, так и непроцессуальной формax [1, с. 275]. В то время как другие лица, выполняющие функции представителя в гражданском судопроизводстве и не имеющие статуса адвоката, выполняют такую деятельность исключительно в процессуальной форме.

В данном случае следует учесть и то, что мы придерживаемся позиции, согласно которой непроцессуальная форма деятельности адвоката не только предшествует, но и может сопровождать процессуальную форму, и, как точно отмечает С.В. Кирюшина, «пронизывает все этапы деятельности адвоката» [9, с. 19]. Указанное позволяет сделать вывод о целесообразности использования именно правовой конструкции «процессуальная и непроцессуальная формы деятельности адвоката», а не «процессуальный и непроцессуальный статусы адвоката».

Учитывая уже упоминавшиеся утверждения Н.И. Матузова, указывающие на взаимосвязь, взаимозависимость и нераздельность на практике трех видов статуса лица, можно прийти к выводу о наличии указанной взаимосвязи между правовым статусом адвоката (профессиональным статусом) и статусом адвоката в аспекте осуществления им процессуальной и непроцессуальной форм его деятельности. Аналогичная правовая связь прослеживается и между профессиональным статусом адвоката и статусом адвоката в той или иной отрасли права, в рамках которой адвокат осуществляет предоставление правовой помощи своему клиенту. Однако в данном случае мы не согласны с позицией В.Г. Андрусева, который указывает, что «категории “процессуальное положение адвоката-защитника" и "правовой статус адвоката" соотносятся между собой как часть и целое» [3, c. 5]. Ошибочность позиции автора, как раз и заключается в том, что статус адвоката при осуществлении им процессуальной формы деятельности, наоборот сочетает в себе и статус адвоката, и процессуальный статус того лица, функции которого выполняет адвокат в том или ином виде производства (например, представителя, защитника и т. д.).

\section{Выводы}

Учитывая специфику правового статуса адвоката в разрезе классификации правового статуса личности по характеру (содержанию), можно прийти к выводу, что общий (конституционный) статус лица, являющегося адвокатом, соответствует правовому статусу физического лица; специальный (родовой) статус такого лица составляет совокупность профессиональных прав, обязанностей и других 
элементов статуса, а значит, может получить название профессионального статуса; индивидуальный правовой статус адвоката представляет собой его правовое положение во время предоставления им конкретных видов правовой помощи. В свою очередь, индивидуальный статус адвоката характеризуется возможностью выделения процессуальной и непроцессуальной форм деятельности адвоката при предоставлении правовой помощи. При этом, независимо от того, реализует адвокат процессуальную или непроцессуальную форму своей деятельности, за ним сохраняется профессиональный статус адвоката, и такое лицо должно именоваться адвокат-защитник, адвокат-представитель или же термином «адвокат», например, при предоставлении правовой помощи свидетелю.

Несомненно, что по значению и объему центральное место занимает процессуальная форма деятельности адвоката. При этом ни в коем случае не следует преуменьшать и роль непроцессуальной формы деятельности, которая может предшествовать или сопровождать процессуальную, поскольку определить эффективность деятельности адвоката по оказанию правовой помощи, можно только на основании анализа как процессуальной, так и непроцессуальной формы его деятельности.

\section{СПИСОК ЛИТЕРАТУРЫ}

1. Адвокатура в России : учебник для вузов / под ред. В. И. Сергеева. - 5-е изд., перераб. и доп. - М. : Юстицинформ, 2019. - 548 с.

2. Андрусів, В. Г. Співвідношення правового статусу та процесуального становища адвоката-захисника / В. Г. Андрусів // Плебсологічна оцінка сучасної світової фінансово-економічної кризи і завдань стратегічного менеджменту : матеріали доповідей та виступів II Всеукр. наук.-практ. конф. (м. Київ, 24 квіт. 2009 р.). - Киев : ВПЦ «Київський університет», 2009. - Вип. 2. - С. 195-198.

3. Андрусів, В. Г. Участь адвоката-захисника в суді першої інстанції у кримінальному процесі України : автореф. дис. ... канд. юрид. наук : 12.00.09 / Андрусів Валерій Григорович. - Киев, 2010. - 19 с.

4. Бірюкова, А. М. Процесуальний статус адвоката на досудовому слідстві / А. М. Бірюкова // Часопис Академії адвокатури України. - 2010. № 9(4). - C. 1-5.
5. Венедіктов, А. А. Види професійного спілкування адвоката / А. А. Венедіктов, Ю. Є. Венедіктова // Юридична психологія та педагогіка. 2012. - № 1. - С. 145-152.

6. Гоматина, О. Д. Участие адвоката в гражданском процессе / О. Д. Гоматина // Молодой ученый. - 2019. - № 43 (281). - С. 64-68.

7. Дидык, Э. М. Представительство адвокатом интересов доверителя в конституционном судопроизводстве / Э. М. Дидык //Актуальные проблемы российского права. - 2013. - № 12. - С. 1625-1633.

8. Заботін, В. В. Форми надання правової допомоги в цивільному судочинстві України / В. В. Заботін // Национальный юридический журнал: теория и практика. - 2017. - № 1 (23). - С. 66-70.

9. Кирюшина, С. В. Реализация адвокатом полномочий по защите прав и законных интересов граждан в гражданском судопроизводстве: организационно-правовой аспект : автореф. дис. ... канд. юрид. наук : 12.00.11/ Кирюшина Светлана Викторовна. - М., 2009. - 24 с.

10. Кодекс профессиональной этики адвоката, принят Первым Всероссийским съездом адвокатов 31 января 2003 года. - Электрон. текстовые дан. Режим доступа: http:/www.fparf.ru/documents/ normative acts/1059. - Загл. с экрана.

11. Колоколова, Э. Е. Адвокат-представитель в российском гражданском процессе : автореф. дис. ... канд. юрид. наук : 12.00.15 / Колоколова Элеонора Евгеньевна. - Саратов, 2005. - 33 с.

12. Леонтьева, Е. А. О деятельности адвоката-представителя в гражданском судопроизводстве / Е. А. Леонтьева // Адвокатская практика. 2008. - № 4. - C. 13-15.

13. Мартынчик, Е. Г. Адвокатское расследование в уголовном процессе. Теоретико-методологические основы доктрины адвокатского расследования / Е. Г. Мартынчик. - М. : Юрист, 2009. -258 с.

14. Об адвокатской деятельности и адвокатуре в Российской Федерации: Федеральный закон от 31 мая 2002 года № 63-Ф3. - Доступ из справ.-правовой системы «КонсультантПлюс».

15. Обловацька, Н. О. Поняття адвокатської діяльності в Україні та Росії / Н. О. Обловацька// Адвокат. 2011. - № 11.-C. 45-48.

16. Правила адвокатської етики, затверджені Звітно-виборним з'їдом адвокатів України від 9 червня 2017 року. - Электрон. текстовые дан. Режим доступа: https://zib.com.ua/files/Pravila AdvokatskojiEtiki2017.pdf. - Загл. с экрана.

17. Про адвокатуру та адвокатську діяльність : Закон України від 5 липня 2012 р. № 5076-VI // Офіційний вісник України. - 2012. - № 62. - Ст. 17.

18. Рагулин, А. В. Профессиональные права адвоката-защитника в Российской Федерации. Вопросы теории и практики : дис. ... д-ра юрид. наук : 
B.B. Заборовский. Особенности процессуальной и непроцессуальной форм деятельности адвоката

12.00.11 / Рагулин Андрей Викторович. - М., 2014. $462 \mathrm{c}$.

19. Ромашов, Р. А. Теория государства и права : учебник и практикум для академ. бакалавриата. М. : Юрайт, 2019. - 443 с.

20. Сивкова, Е. С. Правовые основы статуса и деятельности адвоката в гражданском процессе / Е. С. Сивкова // Актуальные вопросы политики и права. - 2019. - № 12 (39). - Электрон. текстовые дан. - Режим доступа: https://alley-science.ru/ domains_data/files/04December2019/PRAVOVYE\%

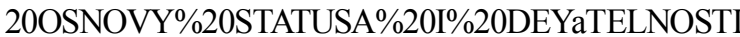
$\%$ 20ADVOKATA $\% 20 \mathrm{~V} \% 20$ GRAZhDANSKOM $\% 20$ PROCESSE.pdf. - Загл. с экрана.

21. Теория государства и права : курс лекций / под ред. Н. И. Матузова, А. В. Малько. - 2-е изд., перераб. и доп. - М. : Юристъ, 2001. - 776 с.

22. Федотова, Т. А. Адвокатская деятельность и проблемы судебного представительства : автореф. дис. ... канд. юрид. наук : 12.00.11 / Федотова Татьяна Александровна. - М., 2009. - 25 с.

23. Юридична енциклопедія : в 6 т. Т. 5 : П-С / під ред. Ю. С. Шемшученко (відп. ред.) [та ін.]. Киев : Укр. енцикл., 2003.- 736 с.

\section{REFERENCES}

1. Sergeeva V.I., ed. Advokatura v Rossii: uchebnik dlya vuzov [Advocacy in Russia: Textbook for Universities]. Moscow, Yustitsinform Publ., 2019. 548 p.

2. Andrusiv V.G. Spivvidnoshennya pravovogo statusu ta protsesualnogo stanovyshcha advokatazakhysnyka [Correlation of Legal Status and Procedural Position of the Lawyer-Defender]. Plebsologichna otsinka suchasnoyi svitovoyi fInansovo-ekonomichnoyi kryzy i zavdan strategichnogo menedzhmentu: materialy dopovidey ta vystupiv II Vseukr. nauk.-prakt. konf. (m. Kyyiv, 24 kvit. 2009 r.). Kiev, VPTs "Kyyivskyy universytet", 2009, no. 2, pp. 195-198.

3. Andrusiv V.G. Uchast advokata-zakhysnyka $v$ sudi pershoyi instantsii u kriminalnomu protsesi Ukrayiny: avtoref. dis. ... kand. jurid. nauk: 12.00.09 [The Fate of Attorney-at-Law in the Court of Criminal Justice in the Criminal Proceedings of Ukraine. Cand. jurid. sci. diss.] Kiev, 2010. 19 p.

4. Biryukova A.M. Protsesualnyy status advokata na dosudovomu slidstvi [The Procedural Status of a PreTrial Attorney]. Chasopys Akademii advokatury Ukrayiny [Chasis of the Academy of Advocacy of Ukraine], 2010, no. 9(4), pp. 1-5.

5. Venediktov A.A., Venediktova Yu.E. Vydy profesiynogo spilkuvannya advokata [Types of Professional Communication of a Lawyer]. Yurydychna psyhologiya ta pedagogika [Legal Psychology and Pedagogy], 2012, no. 1, pp. 145-152.
6. Gomatina O.D. Uchastie advokata v grazhdanskom protsesse [The Participation of a Lawyer in Civil Proceeding]. Molodoy uchenyy [Young Scientist], 2019, no. 43 (281), pp. 64-68.

7. Didyik E.M. Predstavitelstvo advokatom interesov doveritelya $\mathrm{V}$ konstitutsionnom sudoproizvodstve [Representation by a Lawyer of the Interests of a Principal in Constitutional Proceedings]. Aktualnye problemy rossiyskogo prava [Actual Problems of Russian Law], 2013, no. 12, pp. 1625-1633.

8. Zabotin V.V. Formy nadannya pravovoyi dopomogy v tsyvilnomu sudochynstvi Ukrayiny [Forms of Providing Legal Assistance in Civil Proceedings of Ukraine]. Natsionalnyy yuridicheskiy zhurnal: teoriya i praktika [National Legal Journal: Theory and Practice], 2017, no. 1 (23), pp. 66-70.

9. Kiryushina P.V. Realizatsiya advokatom polnomochiy po zashchite prav i zakonnykh interesov grazhdan $v$ grazhdanskom sudoproizvodstve: organizatsionno-pravovoy aspekt: avtoref. dis. ... kand. jurid. nauk: 12.00.11 [Implementation by a Lawyer of Authority to Protect the Rights and Legitimate Interests of Citizens in Civil Proceedings: Organizational and Legal Aspect. Cand. jurid. sci. diss. abs.]. Moscow, 2009. 24 p.

10. Kodeks professionalnoy etiki advokata, prinyat Pervym Vserossiyskim syezdom advokatov 31 yanvarya 2003 goda [The Code of Professional Ethics of the Lawyer Adopted by the First All-Russian Congress of Lawyers on 31 January 2003]. URL: http:// www.fparf.ru/documents/normative_acts/1059 (Accessed 30 June 2020).

11. Kolokolova E.E. Advokat-predstavitel v rossiyskom grazhdanskom protsesse: avtoref. dis. ... kand. jurid. nauk: 12.00.15 [Representative Attorney in the Russian Civil Procedure. Cand. jurid. sci. diss. abs.]. Saratov, 2005. 33 p.

12. Leonteva E.A. O deyatelnosti advokatapredstavitelya $\mathrm{v}$ grazhdanskom sudoproizvodstve [On the Activities of a Representative Lawyer in Civil Proceedings]. Advokatskaya praktika [Law Practic], 2008, no. 4, pp. 13-15.

13. Martyinchik E.G. Advokatskoe rassledovanie v ugolovnom protsesse. Teoretiko-metodologicheskie osnovy doktriny advokatskogo rassledovaniya [Lawyer Investigation in Criminal Proceedings. Theoretical and Methodological Foundations of the Doctrine of the Lawyer's Investigation]. Moscow, Yurist Publ., 2009. 258 p.

14. Ob advokatskoy deyatelnosti $i$ advokature $v$ Rossiyskoy Federatsii: Federalnyiy zakon ot 31 maya 2002 goda no 63-FZ [On Advocacy and Advocacy in the Russian Federation]. Access from Reference Legal System 'KonsultantPlyus'.

15. Oblovatska N.O. Ponyattya advokatskoyi diyalnosti v Ukrayini ta Rossiyi [Understanding the 
Advocacy in Ukraine and Russia]. Advokat [Attorney], 2011. no. 11, pp. 45-48.

16. Pravyla advokatskoyi etyky, zatverdzheni Zvitno-vybornym zyizdom advokativ Ukrayiny vid 9 chervnya 2017 roku [Rules of Advocacy Ethics approved by the reporting and election Congress of lawyers of Ukraine dated 9 June 2017]. URL: https:// zib.com.ua/files/PravilaAdvokatskojiEtiki2017.pdf (accessed 30 June 2020).

17. Pro advokaturu ta advokatsku diyalnist: Zakon Ukrayiny vid 5 lypnya 2012 r. no. 5076-VI [On the Bar and Advocacy Law of Ukraine no. 5076-VI of 5 July 2012]. Ofitsiynyy visnyk Ukrayiny, 2012, no. 62, pp. 17.

18. Ragulin A.V. Professionalnyie prava advokata-zashchitnika $v$ Rossiyskoy Federatsii. Voprosy teorii i praktiki: dis. ... d-ra jurid. nauk: 12.00.11 [Professional Rights of a Defense Lawyer in the Russian Federation. Questions of Theory and Practice. Cand. jurid. sci. diss.]. Moscow, 2014. 462 p.

19. Romashov R.A. Teoriya gosudarstva i prava. Uchebnik i praktikum dlya akademicheskogo bakalavriata [Theory of State and Law. Textbook and
Workshop for Academic Undergraduate]. Moscow, Yurayt Publ., 2019. 443 p.

20. Sivkova E.P. Pravovye osnovy statusa $i$ deyatelnosti advokata $v$ grazhdanskom protsesse [Legal Basis of the Status and Activities of a Lawyer in Civil Proceedings]. Aktualnye voprosy politiki i prava [Actual Issues of Politics and Law], 2019, no. 12 (39). URL: https:// alley-science.ru/domains_data/files/04December2019 /PRAVOVYE\%20OSNOVY\%20STATUSA\%20I\% 20DEYaTELNOSTI\%20ADVOKATA\%20V\%20GRAZh DANSKOM\%20PROCESSE.pdf(accessed 30 June2020).

21. Matuzova N.I., Malko A.V., eds. Teoriya gosudarstva i prava: kurs lektsiy [Theory of State and Law: Lecture Course]. Moscow, Yurist Publ., 2001. $776 \mathrm{p}$.

22. Fedotova T.A. Advokatskaya deyatelnost $i$ problemy sudebnogo predstavitelstva: avtoref. dis. ... kand. jurid. nauk: 12.00.11 [Advocacy and Problems of Judicial Representation. Cand. jurid. sci. diss. abs.]. Moscow, 2009. 25 p.

23. Yurydychna entsiklopediya: v 6t. T. 5: P-S. [Legal Encyclopedia: in 6 Volumes]. Yu.P. Shemshuchenko, et al., eds. Kiev, Ukr. entsikl. Publ., 2003. 736 p.

\section{Information About the Author}

Viktor V. Zaborovsky, Doctor of Sciences (Jurisprudence), Professor, Department of Civil Law and Procedure, Uzhgorod National University, Kapitulnaya St, 26, 88017 Uzhgorod, Ukraine, zaborovskyviktor@gmail.com, https://orcid.org/0000-0002-5845-7535

\section{Информация об авторе}

Виктор Викторович Заборовский, доктор юридических наук, профессор кафедры гражданского права и процесса, Ужгородский национальный университет, ул. Капитульная, 26, 88017 г. Ужгород, Украина, zaborovskyviktor@gmail.com, https://orcid.org/0000-0002-5845-7535 